\title{
Functionally Graded Al Foam Fabricated by Sintering and Dissolution Process with Remaining Spacers
}

\author{
Yoshihiko Hangai $^{1}$, Kousuke Zushida ${ }^{1, *}$, Osamu Kuwazuru ${ }^{2}$ and Nobuhiro Yoshikawa ${ }^{3}$ \\ ${ }^{1}$ Graduate School of Science and Technology, Gunma University, Kiryu 376-8515, Japan \\ ${ }^{2}$ Graduate School of Engineering, University of Fukui, Fukui 910-8507, Japan \\ ${ }^{3}$ Institute of Industrial Science, The University of Tokyo, Tokyo 153-8505, Japan
}

Functionally graded materials composed of $\mathrm{Al}$ foam and $\mathrm{Al}$ /spacer composites were fabricated by a sintering dissolution process, in which removal of the spacers was stopped during the dissolution process. The deformation of the material started in the low-strength Al foam layer then in the high-strength layer with the remaining spacers. [doi:10.2320/matertrans.M2015404]

(Received November 2, 2015; Accepted February 1, 2016; Published April 1, 2016)

Keywords: cellular materials, functionally graded materials, X-ray CT, space holder

\section{Introduction}

Open-cell metallic foam is expected to be used for components in automobiles owing to its superior shock absorbance and light weight ${ }^{1)}$. A space holder method is a promising process for fabricating open-cell metallic foam owing to its control of the pore structures. In this process, a metal/spacer composite is first fabricated by a casting process $^{2)}$ or by a powder metallurgy process ${ }^{3-5)}$. Thereafter, the spacers are removed from the composite, resulting in the formation of pores in the metal. During the removal process of the spacers, two regions exist. One is the metallic foam region in which spacers have already been removed, and the other is the region with remaining spacers (hereinafter "spacer region”). In the spacer region, it is considered that the metallic foam is reinforced by the spacer particles. Previous studies ${ }^{6)}$ indicated that the compression deformation of a metal/spacer composite, which has both a metallic foam region and a spacer region, first occurs in the metallic foam layer and then in the spacer layer. This deformation behavior is similar to that of functionally graded (FG) metallic foam, in which the compression properties vary with the position and deformation sequentially occurs from the lower-strength layers to the higher-strength layers ${ }^{7,8)}$. Also, it was shown that the compression properties of a metal/spacer composite change with the percentage of the spacer region in the composite. Therefore, it is expected that FG metallic foam with a gradual change in its mechanical properties, which depend on the removal time of the spacers, can be realized by forming a metal/spacer composite.

In this study, an FG aluminum (Al)/sodium chloride $(\mathrm{NaCl})$ composite was fabricated by a sintering and dissolution process $(\mathrm{SDP})^{3)}$, using $\mathrm{NaCl}$ as the spacers, so that the removal of spacers is easily achieved by simply immersing the $\mathrm{Al} / \mathrm{NaCl}$ composite in water. First, the $\mathrm{Al} / \mathrm{NaCl}$ composite was observed nondestructively by X-ray computed tomography (CT) during the spacer removal process to reveal the changes in the three-dimensional region in which $\mathrm{NaCl}$ remained (hereinafter "NaCl region") to confirm that two layers, i.e., an $\mathrm{Al}$ foam layer and a $\mathrm{NaCl}$ layer, actually exist in

*Graduate Student, Gunma University the FG material. Second, a compression test specimen with a remaining $\mathrm{NaCl}$ weight ratio of approximately $10 \%$ was fabricated. The deformation behavior during compression tests of the specimen was nondestructively observed by X-ray CT and the mechanical properties of the $\mathrm{FG} \mathrm{Al} / \mathrm{NaCl}$ composite were investigated. From these nondestructive observations, the effect of the $\mathrm{NaCl}$ region in the $\mathrm{Al} / \mathrm{NaCl}$ composite on the mechanical properties and deformation behavior of the $\mathrm{Al}$ foam was investigated.

\section{Experimental Procedure}

Commercially available as-received pure $\mathrm{Al}$ (99.9\% purity, average diameter of $20 \mu \mathrm{m})$ and $\mathrm{NaCl}(99.9 \%$ purity, diameter range from $300 \mu \mathrm{m}$ to $425 \mu \mathrm{m}$ ) powders were thoroughly mixed with a $\mathrm{NaCl}$ volume fraction of $74 \%$. The mixture was then subjected to spark plasma sintering using an SPS-515L (Sumitomo Coal Mining Co., Ltd.). The sintering temperature, pressure, and time were fixed to $843 \mathrm{~K}, 20 \mathrm{MPa}$, and 10 min, respectively ${ }^{9)}$. Two cylindrical $\mathrm{Al} / \mathrm{NaCl}$ composite specimens with dimensions of $\phi 20 \mathrm{~mm} \times 13.8 \mathrm{~mm}$ were obtained.

$\mathrm{NaCl}$ was removed from the specimen by leaching in a water bath. The water temperature was set at $333 \mathrm{~K}$. The amount of remaining $\mathrm{NaCl} \varphi$ was determined as the weight fraction of the $\mathrm{NaCl}$ remaining in the specimen relative to the total amount of $\mathrm{NaCl}$ in the initial specimen as follows;

$$
\varphi=\left(1-\frac{W_{\text {init }}-W_{\text {comp }}}{W_{\text {init }} \times f}\right) \times 100,
$$

where $W_{\text {init }}$ is initial weight of the as-sintered specimen before the removal process, $W_{\text {comp }}$ is the weight of the specimen during the removal process, and $f$ is the weight of $\mathrm{NaCl}$ as a fraction of the initial weight of the as-sintered specimen, i.e., $W_{\text {init }} \times f$ is the weight of $\mathrm{NaCl}$ in the initial as-sintered specimen.

One of the specimens was subjected to a stepwise removal process. At fixed intervals during the removal process, the specimen was pulled out of the water bath and dried, then an $\mathrm{X}$-ray CT observation of the remaining $\mathrm{NaCl}$ was conducted and the specimen was weighted, then the next removal process was conducted. The relationship between the leaching 


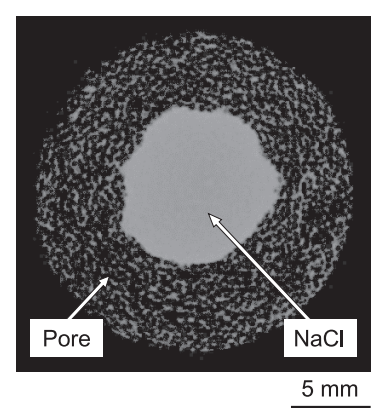

Fig. 1 X-ray CT image of the specimen $(\varphi=11.1 \%)$.

time and the weight fraction of the remaining $\mathrm{NaCl}$ was obtained along with the three-dimensional $\mathrm{NaCl}$ distribution in the specimen during the removal process.

The other specimen was subjected to an uninterrupted removal process to obtain a compression test specimen with $\varphi=$ $11.1 \%$. This specimen was subjected to a stepwise compression test. The deformation behaviors of the specimen and the remaining $\mathrm{NaCl}$ during the compression tests were nondestructively observed by X-ray CT.

X-ray CT observations were conducted using an SMX225CT microfocus X-ray CT system (Shimadzu Corporation ${ }^{7,8)}$. The resolution of each CT image was $512 \times 512$ and the pixel length was approximately $70 \mu \mathrm{m}$. Figure 1 shows a representative two-dimensional cross-sectional X-ray CT image of the specimen. Gray regions indicate the cell walls of $\mathrm{Al}$ foam and $\mathrm{NaCl}$, and black regions indicate pores. To obtain three-dimensional images of the $\mathrm{NaCl}$ region in the specimens, a voxel model of each specimen was constructed using VOXELCON image-processing software (Quint Corporation). First, two-dimensional cross-sectional X-ray CT images were stacked, then an appropriate threshold was set to distinguish $\mathrm{NaCl} / \mathrm{Al}$ and pore voxels to obtain the voxel model.

The specimen $(\varphi=11.1 \%)$ was loaded in a stepwise manner during the compression tests. After each step of compression, the specimen was unloaded, an X-ray CT observation was conducted, then the next compression was conducted. The compression tests were carried out using an Autograph AG-100kNG universal testing machine (Shimadzu Corporation) at a strain rate of $3.3 \times 10^{-3} \mathrm{~s}^{-1}$. After each loading and unloading process, the specimen was placed in the X-ray CT equipment and nondestructive observations were conducted. Series of deformation images were observed with an interval of $2.5 \%$ compression strain for a total compression strain of $0-40 \%$ and with an interval of $10 \%$ compression strain for a total compression strain of 40-80\%. After X-ray CT observation, the specimen was returned to the universal testing machine and subjected to the next compression.

\section{Experimental Results and Discussion}

Figure 2(a) shows the relationship between the leaching time $t$ and $\varphi$. The specimen before the removal process (i.e., $\varphi=100 \%)$ is also shown in the figure. Figures 2(b)-(g) show three-dimensional images of the $\mathrm{NaCl}$ region during the removal process. The remaining $\mathrm{NaCl}$ appeared as a white region, and the cell walls of the pores appeared as a faint white region. The size of the $\mathrm{NaCl}$ region gradually decreased with
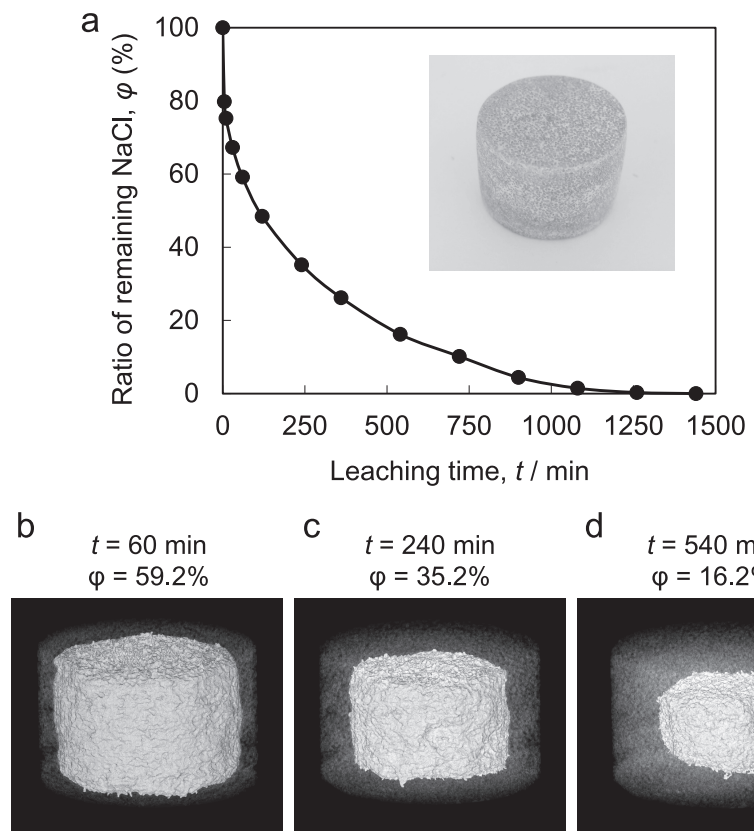

C

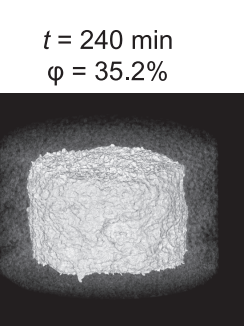

d
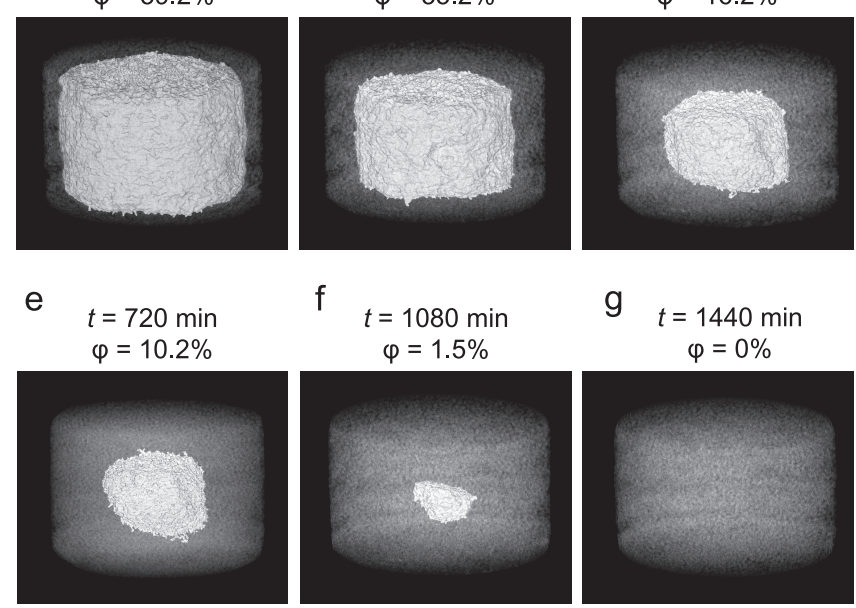

g $t=1440 \mathrm{~min}$ $\varphi=0 \%$

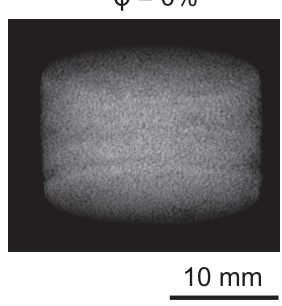

Fig. 2 (a) Relationship between ratio of remaining $\mathrm{NaCl}$ and leaching time along with appearance of as-sintered $\mathrm{Al} / \mathrm{NaCl}$ composite before removal process. (b)-(g) NaCl region in the specimen with (b) $\varphi=59.2 \%$, (c) $\varphi=$ $35.2 \%$, (d) $\varphi=16.2 \%$, (e) $\varphi=10.2 \%$, (f) $\varphi=1.5 \%$, and (g) $\varphi=0 \%$.

increasing leaching time. The reduction of the size of the $\mathrm{NaCl}$ region started from the outside of the specimen, where water could directly come into contact with $\mathrm{NaCl}$, whereas $\mathrm{NaCl}$ remained at the center part of the specimen. Although the area of $\mathrm{NaCl}$ in the $\mathrm{NaCl}$ layer gradually decreased and the area of $\mathrm{Al}$ foam increased with increasing leaching time, two layers, $\mathrm{Al}$ foam and $\mathrm{NaCl}$ layers, can be clearly observed.

Figure 3 shows sequential deformation images of the specimen $(\varphi=11.1 \%)$ during the compression tests. The deformation first occurred in the upper and lower $\mathrm{Al}$ foam layers and then in the $\mathrm{NaCl}$ layer. Figure 4 shows the stress-strain curve of the specimen $(\varphi=11.1 \%)$ and the Young's modulus, which was evaluated from the slope of the stress-strain curve obtained in the unloaded state during the stepwise compression tests, along with the stress-strain curve of the $\mathrm{Al}$ foam $(\varphi=$ $0 \%)^{6}$. Figure 5 shows the normalized volume of the remaining $\mathrm{NaCl}$ at each compression strain. The stress-strain curve of the specimen was similar to that of the $\mathrm{Al}$ foam up to $\varepsilon=$ $20 \%$. In this stage, only the upper and lower $\mathrm{Al}$ foam layers deformed (Fig. 3) and the volume of $\mathrm{NaCl}$ hardly decreased (Fig. 5). Therefore, almost the same plateau region as that for Al foam can be observed, as well as an almost constant Young's modulus. At $\varepsilon=20-40 \%$, the stress increased gradually apart from the plateau regions of the $\mathrm{Al}$ foam. However, the upper and lower $\mathrm{Al}$ foam layers still deformed, and the 


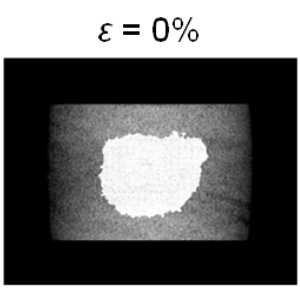

$\varepsilon=40 \%$
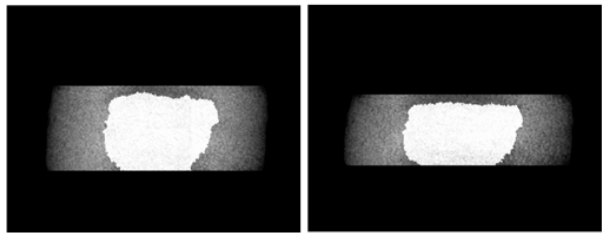

$\varepsilon=20 \%$

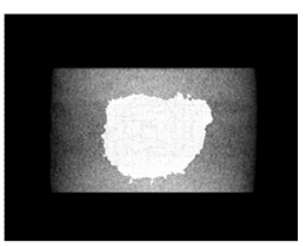

$\varepsilon=50 \%$
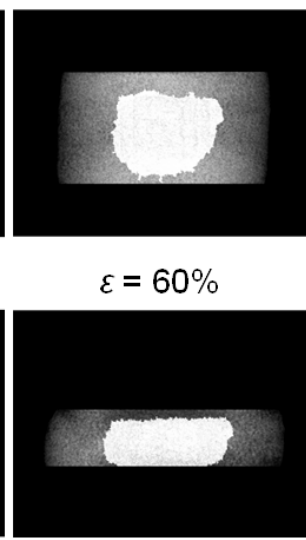

$\varepsilon=30 \%$

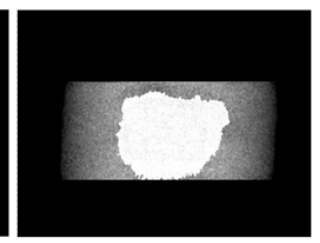

$\varepsilon=70 \%$

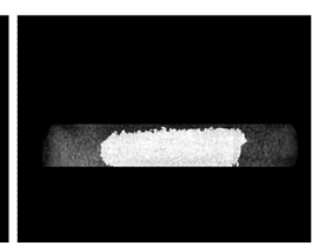

$10 \mathrm{~mm}$

Fig. 3 Deformation images during compression tests of $\mathrm{Al} / \mathrm{NaCl}$ composite $(\varphi=11.1 \%)$.

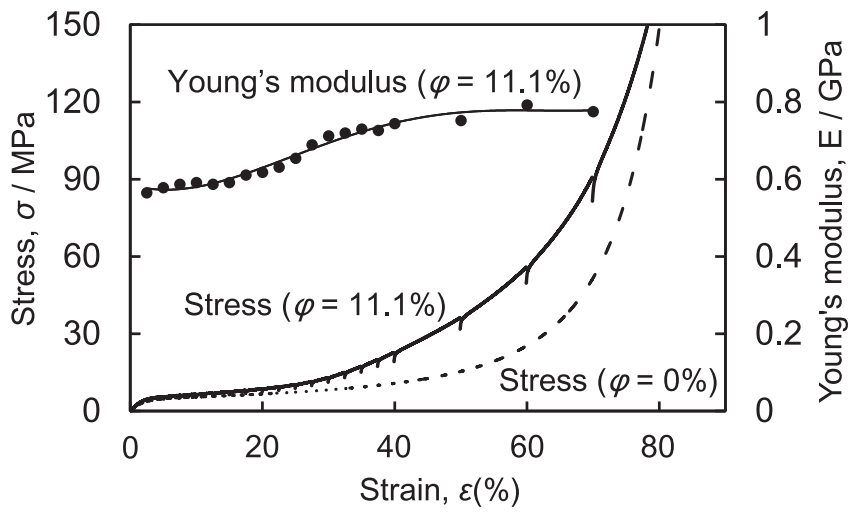

Fig. 4 Stress-strain curve for $\mathrm{Al} / \mathrm{NaCl}$ composite $(\varphi=11.1 \%)$ and Young's modulus plotted against strain along with stress-strain curve of $\mathrm{Al}$ foam $(\varphi=0 \%)^{6}$.

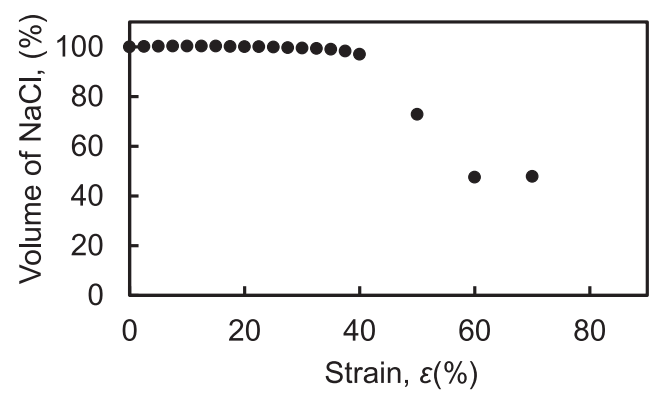

Fig. 5 Volume of $\mathrm{NaCl}$ region at each compression strain.

$\mathrm{NaCl}$ region approximately retained its initial shape and volume (Figs. 3 and 5), i.e., the $\mathrm{NaCl}$ layer hardly deformed. Therefore, it is considered that densification of the upper and lower Al foam layers occurred, and thus, the stress and Young's modulus increased. At $\varepsilon=40-60 \%$, the stress increased markedly. The $\mathrm{NaCl}$ layer started to deform (Fig. 3) and the volume of $\mathrm{NaCl}$ rapidly decreased (Fig. 5). The Young's modulus exhibited an almost constant value that was higher than the value at $\varepsilon<20 \%$. This tendency was consistent with the results of other $\mathrm{FG} \mathrm{Al}$ foam fabricated by the precursor foaming process ${ }^{7)}$. Consequently, it was found that percentage of $\mathrm{NaCl}$ remaining in the $\mathrm{Al} / \mathrm{NaCl}$ composite can be used to control its deformation behavior and mechanical properties, and thus produce tailored FG materials. Clearly, further studies are necessary, such as to compare Young's modulus between the FG Al foam and $\mathrm{Al}$ foam $(\varphi=0 \%)$, to reveal the accurate mechanical properties of the FG Al foam.

\section{Conclusion}

In this study, an FG material composed of an $\mathrm{Al}$ foam region and an $\mathrm{Al} / \mathrm{NaCl}$ composite region was fabricated by a sintering and dissolution process. From the X-ray CT observation carried out during the removal of $\mathrm{NaCl}$ spacers from the $\mathrm{Al} / \mathrm{NaCl}$ composite, it was shown that the size of the $\mathrm{NaCl}$ region gradually decreased with increasing leaching time. Two layers, $\mathrm{Al}$ foam and $\mathrm{NaCl}$ layers, were clearly observed in the composite. From the compression test of the $\mathrm{Al} /$ $\mathrm{NaCl}$ composite $(\varphi=11.1 \%)$, it was found that the deformation first occurred in the $\mathrm{Al}$ foam layer with low strength and then in the $\mathrm{NaCl}$ layer with high strength. Therefore, the percentage of $\mathrm{NaCl}$ remaining in the $\mathrm{Al} / \mathrm{NaCl}$ composite can be used to control its deformation behavior and mechanical properties, and thus produce tailored FG materials.

\section{REFERENCES}

1) J. Banhart: Prog. Mater. Sci. 46 (2001) 559-632.

2) C. San Marchi and A. Mortensen: Acta Mater. 49 (2001) 3959-3969.

3) Y.Y. Zhao and D.X. Sun: Scr. Mater. 44 (2001) 105-110.

4) A. Hassani, A. Habibolahzadeh and H. Bafti: Mater. Des. 40 (2012) 510-515.

5) Y. Hangai, K. Zushida, O. Kuwazuru and N. Yoshikawa: J. Mater. Process. Technol. 214 (2014) 1721-1727.

6) Y. Hangai, H. Yoshida, R. Yamaguchi, O. Kuwazuru and N. Yoshikawa: Mater. Trans. 54 (2013) 850-853.

7) Y. Hangai, K. Takahashi, R. Yamaguchi, T. Utsunomiya, S. Kitahara, O Kuwazuru and N. Yoshikawa: Mater. Sci. Eng. A 556 (2012) 678-684.

8) Y. Hangai, K. Saito, T. Utsunomiya, O. Kuwazuru and N. Yoshikawa: Mater. Sci. Eng. A 613 (2014) 163-170.

9) M. Hakamada, Y. Yamada, T. Nomura, Y.Q. Chen, H. Kusuda and M. Mabuchi: Mater. Trans. 46 (2005) 2624-2628. 